\title{
A narrative on the fabrication of results in science
}

\author{
João Freitas*, Dulce Esteves and Henrique Neiva
}

Data fabrication is an act of scientific misconduct that affects its transparency and veracity. In this study we identify the main data fabrication problems in scientific research and suggest prevention methodologies. This article is a narrative review of the major articles in fabrication of results in science. The results of this review provide the knowledge that fabrication cases come from most diverse scientific fields. Currently, there is more pressure on scientists to publish. As a result, several studies now report on data fabrication in research. State laws and research ethics committees strengthen relationships to criminalize this type of misconduct that usurps state funds. This study discusses the controversies and complexities of data fabrication in scientific research. Ethics committees must continue their efforts to prevent data fabrication, thus contributing to scientific transparency.

Keywords: Criminalization, data fabrication, scientific misconduct, transparency.

SCIENTIFIC misconduct does not stop with a decline in morality and increase in competition in obtaining research funds. Instead, very well structured, accusations of scientific misconduct, stand in the history of science itself from ancient Greece to the present day ${ }^{1}$. Although the respective federal agencies nuclearize the concept of scientific conduct to review and disseminate research, experts have a more popular view ${ }^{2}$. According to the Council of Scientific Editors (CSE), scientific misconduct is 'the behaviour of a researcher, whether intentional or not, which falls short of a good ethical and scientific standard'?

Currently, there is pressure on researchers to publish frequently and in high-impact journals ${ }^{4}$. Bibliometric assessment is used to enhance productivity and distribution of resources ${ }^{5-8}$. However, in another way, the financial resources available for such efforts are clearly inadequate. Therefore, competition for these limited funds has created a hostile environment and is highly favourable to the appearance of scientific misconduct.

The competitive level in science is changing and concerns that this may alter scientific knowledge are being debated $^{9-11}$. The findings of published research are sometimes refuted by subsequent evidence, resulting in confusion and disappointment ${ }^{12}$. Between 2000 and 2017, 15,000 articles were published on research misconduct ${ }^{13}$.

João Freitas is in the Sport Science School of Rio Maior, Polytechnic Institute of Santarém, Portugal; Dulce Esteves and Henrique Neiva are in the University of Beira Interior: Department of Sports Sciences, UBI, Covilhã, Portugal and Research Centre in Sport Sciences, Health Sciences and Human Development, Portugal.

*For correspondence. (e-mail: jdfreitas12@gmail.com)
Current data show that, the success rate of eligible proposals in the Universities for the year 2015 was only $14 \%$; as governments decrease funding, the pressure on universities to obtain funding from other sources increases, including the UE and the private sector ${ }^{13}$.

Data fraud can have four types of external effects ${ }^{14}$. It can damage the career of colleagues and students, who unknowingly co-write articles with a fraudulent researcher. In clinical cases, patients may suffer due to lack of information about the effectiveness of different treatment options. Fraud can slow down scientific progress, because researchers waste precious resources (funds as well as time) trying to follow the clues from dubious research. Finally, notes on scientific fraud damage the image of the field in which the fraud was committed and reduce the confidence of science. Scientists involved in fraudulent research can face adverse social, financial and legal consequences ${ }^{15}$. Recently, a study of 10,500 articles retracted until 2016 showed that $0.04 \%$ was retracted; the annual retraction rate was around 1000 . The rate of increase is slowing down since 2012, and $43 \%$ of the 946 articles retracted in 2014 were due to FFP (fabrication, falsification and plagiarism) ${ }^{16}$.

Literature on ethics in scientific research shows the frequency of production of results, increasing society's lack of trust in the scientific community. Thus, the present study reviews the results of data fabrication in science.

\section{Methodology}

We began with a narrative review of the literature to analyse data fabrication in science, followed by a synthesis 
of the results, combined with a reflective perspective from the authors. The study was carried during November-December 2020 using the databases PubMed and Google Scholar. The inclusion criteria were (1) complete articles and (2) English or Portuguese language. The articles focused on data fabrication in science, on authors and their responsibilities on the fabrication and misconduct in scientific research and the ways of preventing them. Exclusion criteria were: (1) abstracts, (2) conference proceedings, (3) general science misconduct articles and (4) books. The search resulted in 56 articles from a diversified list of scientific fields. We then synthesized the main concepts on data fabrication.

\section{Data fabrication}

Data fabrication is a large concept in society and it is essential to distinguish it in the context of the ethical problems of scientific research. In this context fabrication is the report of a set, total or partial, of data that does not exist and were invented. For this, the way to obtain them is forged, or includes the description of experiences that have never been carried out ${ }^{17,18}$. As the opposite of telling the truth, the quintessential form of conduct of unethical research, but when the scientific baggage is removed, fabrication represents the activity of combining, shaping and/or organizing the elements as a whole for a specific purpose ${ }^{19}$.

During studies, misunderstandings between fabrication (presentation of facts or unproven data) and falsification (alteration or selection of certain data to obtain the desired results) should be strictly avoided ${ }^{20}$. Particularly in the scientific community in the United States, fabrication is considered a form of research misconduct, often associated with the term 'falsification',

\section{Fabrication, falsification and plagiarism}

Despite the causes and estimates of misconduct in scientific research, the problem remains diverse. The literature suggests that scientific misconduct, namely fabrication, falsification and plagiarism in research, continues to damage public health and confidence in science. Thus, it should be relevant to establish the concepts and the consequent differences.

During studies, misunderstandings between fabrication (presentation of facts or unproven data) and falsification (alteration or selection of certain data to obtain the desired results) should be strictly avoided ${ }^{20}$. Some of the great scientists of the past such as Galileo, Newton, Dalton, Mendel, Millikan and Einstein have been accused of fabricating, falsifying and plagiarizing data ${ }^{21,22}$. Both fabrication and falsification are ways of lying about the data reported in an article ${ }^{23}$. Forgery is manipulating materi- als, equipment or research processes, or altering or omitting data or results so that the research is not accurately represented in the search log.

Plagiarism is qualitatively different from the other two because it does not distort scientific knowledge, although it has important consequences on the career of those involved and, therefore, on the entire scientific community $^{24}$.

\section{The frequency of fabrication in science}

There is a notion that fabricated results tend to be uncovered due to the self-regulatory mechanism of research regulation ${ }^{25}$. This is certainly far from the truth, leading many scientists to believe that no action on their part is necessary.

According to a survey of 549 students at the University of California, $15 \%$ admitted that they would be willing to select, omit, or fabricate data to win a grant or publish a paper $^{26}$. In a similar survey, $7 \%$ of postdocs at the University of California, San Francisco, said they were willing to select or omit data to improve their results ${ }^{27}$.

Judith Swazey and her colleagues, covering undergraduate students and professors at 99 universities, found that $44 \%$ of students and $50 \%$ of the faculty were aware of two or more types of misconduct, and approximately $10 \%$ observed or had direct knowledge in the manufacture of $\mathrm{data}^{28}$. The American Association for the Advancement of Science surveyed a random sample of its members and $27 \%$ of respondents said they admitted that they found or witnessed research that was fabricated, falsified or plagiarized in the past 10 years ${ }^{29}$.

A meta-analysis of published research was done that asked scientists whether they or their peers had already committed acts of scientific misconduct. Approximately $2 \%$ of respondents admitted to having committed scientific misconduct and 14\% reported knowledge of such behaviour by their peers ${ }^{30}$. In the same context, it is suggested that there is evidence consistent with the 'deliberate fraud' hypothesis; the results suggest that articles based on manufactured or falsified data represent a calculated effort to deceive, inferring that obviousness is not naive, irresponsible or inadvertent ${ }^{31}$.

The case of Diederik Stapel, that published more than 50 influential studies, including subjects that indicate dirty environments encourage racism, that eating meat makes people selfish and that power undermines morality. Some of these studies elevated his academic career, before some of his students denounced him $^{32}$.

In the last four decades, there has been a tenfold increase in retractions for fraud or suspected fraud since 1975 (ref. 33). The respective rates have varied between high levels in academic disciplines, such as cell biology and oncology and low levels such as in sociology and political science ${ }^{34}$. This fact reflects that in terms of criteria 
they are more objective and the respective medical consequences are more serious in the area of health than in other social sciences; comparatively in the case of psychology it was an intermediate rate ${ }^{34}$.

The fabrication of data is not restricted to just a laboratory or university. It can be an act with external ramifications $^{35}$.

In a study in the field of social psychology and personality, the authors found that in their sample, researchers had the feeling that the authors presented themselves as 'the field as a whole can be very rotten' ${ }^{36}$. In the field of psychology, over three decades, more than half of the data contained inconsistencies in the report of $P$-values that often led to false conclusions about statistical significance $^{37}$.

Data fabrication in scientific research is not limited to the social sciences, but also in the business world and in the industry.

A study showed that Google secretly paid US\$ 5000400,000 to academics to help prevent changes to the market regulations that maintain the company's dominance ${ }^{38}$. Cases in the food industry have also shown that scientific research financed by certain brands that produce foods whose effects need to be tested, led to results that helped omit or cover up the real harmful consequences on consumers' health ${ }^{38}$. Another case more specifically in the automotive industry was one carried out by a team from West Virginia University, USA, which unmasked Volkswagen's fraudulent and environmental pollution practices regarding its diesel cars $^{39}$.

\section{Criminalization in data fabrication}

The phenomenon of research misconduct is an international concern. In the 1980 s, highly publicized cases of misconduct in Government-funded research in the US, alerted scientists and lawmakers to the importance of the problem. Such misconduct scandals have occurred in many other countries since then, covering Canada, China, Denmark, Germany, Italy, Japan, The Netherlands, South Korea and the United Kingdom ${ }^{40,41}$.

Public policies and scientific ethics committees must guarantee the integrity of science so that discoveries made in a fraudulent manner are not integrated into the body of scientific knowledge. In addition to the administrative performance of the committees, there should be civil law penalty. The use of federal or state funds resulting from false or fraudulent publications can lead to civil penalties.

The general public must expect the punishment for fabrication by scientists to be equivalent to that of other sectors of our society ${ }^{42}$.

Data fraud leads to wasting millions of dollars of Government funds ${ }^{43-45}$ and also poses substantial risks to society and public health ${ }^{46}$, being responsible for thou- sands of deaths ${ }^{47}$. There is widespread agreement among scientists that such behaviour is morally wrong and must be sanctioned ${ }^{44,48,49}$.

In the past three decades, criminalization has been witnessed in scientific research; however, only 39 scientists from seven countries were subject to criminal sanctions between 1979 and 2015 (ref. 48).

One such case is that of Eric Poehlman, a medical scientist at the University of Vermont, USA, who published 10 articles containing fabricated data to support his study of metabolic changes in women. His studies cost the government US\$ 2.9 million and was the first US scientist to be arrested for scientific fraud ${ }^{50}$. Also in the United States, on 1 July 2015, a judge passed a 4.5-year prison sentence and US\$ 7.2 million fine to scientist Dong-Pyou Han for tampering with HIV research data ${ }^{51}$.

Data fabrication in medical research can lead to two major problems. First there will be an erosion of confidence in the general validity of scientific discoveries, which may imply a slowdown in the pace of research, as researchers spend more time trying to confirm the work of others. Secondly, fraud or deception can cause a patient's treatment to be based on less firm scientific evidence, and therefore may not have the expected benefit and possibly cause damage to patients ${ }^{18}$.

In the case of sports science also data fabrication is considered a harmful practice, as it affects the reliability of the data and reduces the validity of research in the long term $^{52}$.

\section{Trends for the future}

Given the current situation, Merton's ${ }^{53}$ concept that scientific ethos is the search for knowledge, which would be produced in compliance with the principles of a scientist's disinterest, the spirit of community and the sharing of knowledge among peers is not valid is out of the question.

The objective of research should be to increase knowledge and develop new ideas with important consequences to the whole society. Due to its crucial role, the importance of integrity in research cannot be overestimated ${ }^{54}$. It seems evident that policies of scientific misconduct are not just a good idea, but a need ${ }^{55}$.

Investigating and prosecuting allegations of misconduct related to international collaborations can be difficult since different countries have different laws, regulations and policies in relation to research misconduct $^{56}$. Some organizations and academics have requested the global research community to develop international guidelines to harmonize conflicting rules of misconduct $^{15,56,57}$.

The incorruptibility of scientific records, and their precision, dominance and value in the final analysis impact the health and well-being of society. Thus, scientists must 
use the highest possible standards while proposing, conducting, reviewing and reporting research, or when educating and mentoring new researchers ${ }^{58}$. Prevention methods should be emphasized, especially by observers and juries with experience in various stages of research, with regard to academic misconduct.

In the literature and political disputes at the international level on the integrity of research, the focus is on research institutions on a daily basis, with a strong drive to encourage them to strengthen standardized policies, guidelines and operational procedures ${ }^{59}$. However, as analysis demonstrated, that department heads did not seem to use organizational policies in their sense making around research integrity ${ }^{60}$. Science now needs to strengthen relations with economic and political stakeholders ${ }^{61,62}$.

Members of the scientific community draw an ethical distinction between data fraud and selective reporting, but consider both behaviours as immoral and deserving of punishment $^{63}$. In the same vein, several statistical methods are available to evaluate whether the data are likely to be manufactured or not ${ }^{64}$.

\section{Conclusion}

The responsibility for conducting research is the basis for sound scientific practice. Over the past few decades, the scientific community and the respective ethics committees have gained knowledge for improvement in achieving clarity about the results produced, as well as the claims and sanctions associated with this type of practice.

Fabrication is a phenomenon that scientific system has faced since its creation and it is considered a problem that causes losses, and the numbers of its incidences cannot be easily verified by qualitative or quantitative methods.

It is unlikely that a global organization will criminalize this act, but efforts are made to ensure that there are structures for the same. Nevertheless, this type of misconduct will always be associated with scientific research, being not a symbiosis, but a virus. The digital age has opened the doors to a massive amount of data that are simple and easy to access. It also provides tools for the interpretation of data and analysis of scientific discoveries; however, it can increase cases of plagiarism.

Universities, research institutions, Government organizations and other stakeholders must join efforts to elucidate the effects of fabrication on scientific research.

After all, science is the search for truth.

1. Gross, C., Scientific misconduct. Annu. Rev. Psychol., 2016, 67, 393-711.

2. De Vries, R., Anderson, M. S. and Martinson, B. C., Normal misbehaviour: scientists talk about the ethics of research. J. Emp. Res. Human Res. Ethic, 2006, 1, 43-50.

3. Scott-Lichter, D., CSE's white paper on promoting integrity in scientific journal publications, in 2012 Update, Wheat Ridge, CO, Council of Science Editors, 2012, 3rd edn.
4. Lawrence, P. A., The politics of publication-authors, reviewers and editors must act to protect the quality of research. Nature, 2003, 422(6929), 259-261; doi:10.1038/422259a.

5. Warner, J., A critical review of the application of citation studies to the research assessment exercises. J. Inf. Sci., 2000, 26(6), 453-459.

6. Qiu, J., Publish or perish in China. Nature, 2010, 463(7278), 142-143; doi:10.1038/463142a.

7. De Meis, L., Velloso, A., Lannes, D., Carmo, M. S. and de Meis, C., The growing competition in Brazilian science: Rites of passage, stress and burnout. Braz. J. Med. Biol. Res., 2003, 36(9), $1135-1141$.

8. Osuna, C., Crux-Castro, L. and Sanz-Menedez, L., Overturning some assumptions about the effects of evaluation systems on publication performance. Scientometrics, 2011, 86, 575-592.

9. Young, N. S., Ioannidis, J. P. A. and Al-Ubaydi, O., Why current publication practices may distort science. PLoS Med., 2008, 5(10), 1418-1422; doi:10.1371/journal.pmed.0050201.

10. Statzner, B. and Resh, V. H., Negative changes in the scientific publication process in ecology: Potential causes and consequences. Freshw. Biol., 2010, 55(12), 2639-2653; doi:10.1111/ j.1365-2427.2010.02484.x.

11. Ioannidis, J. P. A., Why most published research findings are false. PLoS Med., 2005, 2(8), 696-701.

12. Kornfeld, D. S., It's time for action on research misconduct. Acad. Med., 2018, 93(8), 1103.

13. Lamborelle, A. and Álvarez, L., How much money goes into Europe's universities? Euractiv [consult. a 24.05.2018], 2016; https://www.euractiv.com/section/education/infographic/how-muchmoney-goes-into-europes-universities/

14. Stroebe, W., Postmes, T. and Spears, R., Scientific misconduct and the myth of self-correction in science. Persp. Psycholog. Sci., 2012, 7, 670-688.

15. Resnik, D. B., Data fabrication and falsification and empiricist philosophy of science. Sci. Eng. Ethics, 2014, 20, 423-431.

16. Brainard, J. and You, J., Rethinking retractions. Science, 2018, 362(6413), 391-393.

17. Pimple, K. D., Six domains of research ethics. A heuristic framework for the responsible conduct of research. Sci. Eng. Ethics, 2002, 8(2), 191-205; PMID:12092490.

18. Jaffer, U. and Cameron, A. E., Deceit and fraud in medical research. Int. J. Surg., 2006, 4(2), 122-126.

19. Markham, A., Fabrication as ethical practice. Inf. Commun. Soc., 2012, 15(3), 334-353.

20. Resnik, D. B. and Dinse, G. E., Scientific corrections and retractions related to misconduct findings. J. Med. Ethics, 2012, 39, 4650.

21. Broad, W. and Wade, N., Betrayers of the Truth, Simon \& Shuster, Inc. Publishers, New York, 1982.

22. Corry, L., Renn, J. and Stachel, J., Belated decision in the Hillbert-Einstein priority dispute. Science, 1997, 278(5341), $1270-1273$.

23. Shamoo, A. S. and Resnik, D. B., Responsible Conduct of Research, Oxford University Press, New York, 2009, 2nd edn.

24. Steneck, N. H., Fostering integrity in research: definitions, current knowledge, and future directions. Sci. Eng. Ethics, 2006, 12, $53-74$.

25. Anonymous, $\mathrm{PhD}$ - club or history? Nature, 2004, 429, 789.

26. Kalichman, M. W. and Friedman, P. J., A pilot study of biomedical trainees' perceptions concerning research ethics. Acad. Med., 1992, 67, 769-775.

27. Eastwood, S., Derish, P., Leash, E. and Ordway, S., Ethical issues in biomedical research: perception and practices of postdoctoral research fellows responding to a survey. Sci. Eng. Ethics, 1996, 2, $89-114$.

28. Swazey, J. P., Anderson, M. S. and Louis, K. S., Ethical problems in academic research. Am. Sci., 1993, 81, 542-553. 
29. Titus, S. L., Wells, J. A. and Rhoades, L. J., Repairing research integrity. Nature, 2008, 19(453), 980-982.

30. Fanelli, D., How many scientists fabricate and falsify research? a systematic review and meta-analysis of survey data. PLOS ONE, 2009, 4, e5738.

31. Steen, R. G., Retractions in the scientific literature: Is the incidence of research fraud increasing? J. Med. Ethics, 2011, 37, 249-253.

32. Bhattacharjee, Y., The mind of a con man. New York Times Magazine, 26 April 2013.

33. Fang, F. C., Steen, R. G. and Casadevall, A., Misconduct accounts for the majority of retracted scientific publications. Proc. Natl. Acad. Sci. USA, 2012, 109, 17028-17033.

34. Margraf, J., Zur Lage der Psychologie. Psychol. Rundsch., 2015, 66, $1-30$.

35. Kim, J. and Park, K., Ethical modernization: Research misconduct and research ethics reforms in Korea following the Hwang affair. Sci. Eng. Ethics, 2013, 19(2), 355-380.

36. Motyl, M. et al., The state of social and personality science: Rotten to the core, not so bad, getting better, or getting worse? J. Pers. Soc. Psychol., 2017, 113, 34-58; https://doi.org/10.1037/ pspa0000084.

37. Nuijten, M. B., Hartgerink, C. H., van Assen M. A., Epskamp, S and Wicherts, J. M., The prevalence of statistical reporting errors in psychology (1985-2013). Behav. Res. Methods, 2016, 48, $1205-1226$.

38. Mullins, B. and Nicas, J., Paying Professors: Inside Google's Academic Influence Campaign. The Wall Street J., 2017 [Consult. a 26.2.2021]. Disponível em; https://www.wsj.com/articles/payingprofessors-inside-googles-academic-influence-campaign-1499785286

39. Oehmke, P., The Three Students Who Uncovered Dieselgate, Spiegel Online, 2017 [Consult. a 24.5.2018]. Disponível em; http://www.spiegel.de/international/business/the-three-students-whodiscovered-dieselgate-a-1173686.html

40. Ana, J., Koehlmoos, T., Smith, R. and Yan, L. L., Research misconduct in low and middle-income countries. PLoS Med., 2013, 10(3), e1001315.

41. Resnik, D. B. and Master, Z., Policies and initiatives aimed at addressing research misconduct in high-income countries. PLoS Med., 2013, 10(3), e1001406.

42. Redman, B. K. and Caplan, A. L., Off with their heads: the need to criminalize some forms of scientific misconduct. The J. Law, Med., 2005, 33(2), 345-348.

43. Gammon, E. and Franzini, L., Research misconduct oversight: Defining case costs. J. Health Care Finance, 2013, 40, 75-99.

44. O'Leary, P., Policing research misconduct. Albany Law J. Sci. Technol., 2015, 25, 39-93.

45. Stern, A. M., Casadevall, A., Steen, R. G. and Fang, F. C., Financial costs and personal consequences of research misconduct resulting in retracted publications. eLife, 2014, 3, e02956; doi:10. 7554/eLife.02956.

46. Godlee, F., Smith, J. and Marcovitch, H., Wakefield's article linking MMR vaccine and autism was fraudulent. $B M J, 2011, \mathbf{3 4 2}$, 64-66; doi:10.1136/bmj.c7452.

47. Bouri, S., Shun-Shin, M. J., Cole, G. D., Mayet, J. and Francis, D. P., Meta-analysis of secure randomised controlled trials of bblockade to prevent perioperative death in non-cardiac surgery. Heart, 2014, 100, 456-464; doi:10.1136/heartjnl-2013-304262.

48. Oransky, I. and Abritis, A., Who faces criminal sanctions for scientific misconduct? In 5th World Conference on Research Integ- rity, Amsterdam, The Netherlands, 28-31 May 2017, Abstract Book, page 4, O-003.

49. Judson, H. F., The Great Betrayal: Fraud in Science, Harcourt Inc, Orlando, FL, 2004.

50. Dalton, R., Obesity expert owns up to million-dollar crime. Nature, 2005, 434, 424

51. Neibergall, C., Restoring confidence in research integrity. The Lancet Oncology, 2015, 16(8), 871; https://www.thelancet. com/journals/lanonc/article/PIIS1470-2045(15)00140-0/fulltext (accessed on 8 December 2020).

52. Gaspar, D. and Esteves, M., Awareness of the Misconduct in Sports Science Research. Ann. Appl. Sport. Sci., 2020, e934; http://www.aassjournal.com; e-ISSN: 2322-4479.

53. Merton, R. K., The Sociology of Science. Theoretical and Empirical Investigations, The University of Chicago Press, Chicago, 1973.

54. Mojon-Azzi, S. M. and Mojon, D. S., Scientific misconduct: from salami slicing to data fabrication. Ophthalmologica, 2004, 218 , $1-3$.

55. Steneck, N. H., Research universities and scientific misconduct: history, policies, and the future. J. Higher Educ., 1994, 65, 311329.

56. Boesz, C. and Lloyd, N., Collaborations: investigating international misconduct. Nature, 2008, 452(7188), 686-687; doi:10.1038/452686a.

57. Fondation européenne de la science, \& ALLEA, The European code of conduct for research integrity. European Science Foundation, Strasbourg, 2011.

58. Horner, J. and Minifie, F. D., Research ethics III: Publication practices and authorship, conflicts of interest, and research misconduct. J. Speech, Language, and Hearing, 2011, S346 Research, $54, \mathrm{~S} 346-\mathrm{S} 362$.

59. Bouter, L., What research institutions can do to foster research integrity. Sci. Eng. Ethics, 2020; https://doi.org/10.1007/s11948020-00178-5.

60. Degn, L., Integrating Integrity: The Organizational Translation of Policies on Research Integrity, Science and Engineering Ethics. 2020, 26, 3167-3182; https://doi.org/10.1007/s11948-020-00262-w.

61. Faria, R., Ciência à medida: Conflitos de interesse e interferência na investigação científica financiada. Sociologia [Custom tailored science: Conflicts of interest and interference in commissioned scientific research]. Revista da Faculdade de Letras da Universidade do Porto., 2018, 36, 97-118; doi:10.21747/08723419/ soc36a5.

62. Dal-Ré, R., Bouter, L. M., Cuijpers, P., Gluud, C. and Holm, S., Should research misconduct be criminalized? Res. Ethics, 2020, 16(1-2), 1-12; doi:10.1177/1747016119898400.

63. Pickett, J. T. and Roche, S. P., Questionable, objectionable or criminal? Public opinion on data fraud and selective reporting in science. Sci. Eng. Ethics, 2017; https://doi.org/10.1007/s11948017-9886-2.

64. Al-Marzouki, S., Evans, S., Marshall, T. and Roberts, I., Are these data real? Statistical methods for the detection of data fabrication in clinical trials. $B M J, 2005, \mathbf{3 3 1}(7511), 267 \mathrm{e} 70$.

Received 11 September 2020; re-revised accepted 31 May 2021

doi: $10.18520 / \mathrm{cs} / \mathrm{v} 121 / \mathrm{i} 2 / 205-209$ 